\title{
In Defence of State-Based Reasons to Intend
}

James Morauta*

Abstract. A state-based reason for one to intend to perform an action $\mathrm{F}$ is a reason for one to intend to $\mathrm{F}$ which is not a reason for one to $\mathrm{F}$. Are there any state-based reasons to intend? According to the Explanatory Argument, the answer is no, because statebased reasons do not satisfy a certain explanatory constraint. I argue that whether or not the constraint is correct, the Explanatory Argument is unsound, because state-based reasons do satisfy the constraint. The considerations that undermine the Explanatory Argument also generate a strong, positive case for the existence of state-based reasons to intend.

[A version of this paper appears in the Pacific Philosophical Quarterly (2010).]

\section{State-Based Reasons to Intend}

Just as there can be normative reasons for one to act, so too can there be normative reasons for one to intend to act. Just as there can be normative reasons for me to go out to dinner, or to work on my paper, or to go for a swim, so too can there be normative reasons for me to intend to do these things. But what exactly is the relationship between normative reasons to intend and normative reasons to act? (From now on, unless the context indicates otherwise, "reason" always means normative reason.)

Here's one thing that everybody accepts: where $\mathrm{F}$ is an action, a fact which is a reason for one to intend to $\mathrm{F}$ is typically also a reason for one to $\mathrm{F} .{ }^{1}$ But is that always the case? Let an object-based reason to intend to $\mathrm{F}$ be a fact which is both a reason to intend to $\mathrm{F}$ and a reason to $\mathrm{F}$; and let a state-based reason to intend to $\mathrm{F}$ be a fact which

* Thanks to John Broome and Mark Schroeder for helpful comments.

${ }^{1}$ If you prefer to think of normative reasons as true propositions, and if you think of those as something different from facts, that's fine; translate as required. The questions that I'm interested in here don't turn on this issue. 
is a reason to intend to $\mathrm{F}$ but which is not a reason to $\mathrm{F} .^{2}$ Are there any state-based reasons to intend?

Although there has been a lot of debate about this question, the issue remains controversial. ${ }^{3}$ In this paper I want to examine one particular argument against the possibility of state-based reasons-what I call the Explanatory Argument. According to this argument, state-based reasons are ruled out by a certain explanatory constraint on reasons to intend.

While the Explanatory Argument has not to my knowledge been formulated in the literature, the intuitions that drive the argument are ones that I often encounter in conversations about this topic, and they do, I think, play a significant role in generating the sense of unease that many people have about state-based reasons. Furthermore, as we'll see, each of the premises of the argument has support in the literature, and each is of substantial independent interest. The Explanatory Argument deserves a careful statement and assessment.

Nevertheless, I will claim that we should reject the Explanatory Argument. It's easy for a sense of unease about state-based reasons to linger if it's not forced to make itself explicit. And once we do make this particular sense of unease explicit-in the form of

${ }^{2}$ A word of caution about this terminology: there are quite a few distinctions floating around in the literature that sound a bit like this one. Derek Parfit (2001) distinguishes between "object-given" and "state-given" reasons to have mental states, and others have distinguished between "content-related" and "attitude-related" reasons (Piller 2001), and between "constitutive" and "extrinsic" reasons (Hieronymi 2005, 2006). None of these distinctions are the same as mine. For one thing, they're more general: they also apply to mental states other than intentions. And even when they are restricted to intentions, it's not clear that any of these distinctions are even extensionally equivalent to mine. I'm not importing any of these other distinctions. I use the terms "object-based" and "state-based" just in the straightforward way that I've defined them. Apologies for further cluttering up the lexicon, but none of the existing distinctions are entirely satisfactory for my purposes.

${ }^{3}$ For some recent rejections of state-based reasons to intend, see Goetz 1998; Owens 2000, pp. 81-82; and Enç 2003, pp. 30-37. Recent defences of state-based reasons include Mele 1995, Piller 2001, and Clarke 2007. 
the Explanatory Argument-I think it will become clear that we were wrong to be uneasy. As we'll see, the considerations that undermine the Explanatory Argument also generate a strong, positive case for the existence of state-based reasons to intend. These considerations raise serious doubts about the prospects for any argument against the possibility of state-based reasons.

\section{The Explanatory Argument}

Here's the basic idea behind the Explanatory Argument: there are no state-based reasons to intend because if a fact isn't a reason for one to perform an action F, then it also isn't a reason for one to intend to F; and that's because (so the argument goes) such a fact couldn't be the reason for which one intends to F. Let me expand.

It is standard practice in ethics and action theory to distinguish between claims of the following kinds:

(N) " $\mathrm{M}$ is a reason for $\mathrm{S}$ to $\mathrm{V}$ ".

(E) "M is the reason for which $\mathrm{S} V \mathrm{~V}$ " (or " $\mathrm{M}$ is the reason for which $\mathrm{S}$ is $\mathrm{V}$ ing").

The first claim, (N), is a normative one: it tells us that M counts in favour of S's V-ing, that $\mathrm{M}$ provides some degree of justification for S's V-ing. The second claim, (E), is a psychological one: it tells us that $\mathrm{M}$ is what is motivates $\mathrm{S}$ 's $\mathrm{V}$-ing, that $\mathrm{M}$ is the consideration in the light of which $\mathrm{S}$ is $\mathrm{V}$-ing. The second claim is also an explanatory one: when we say that $\mathrm{M}$ is the reason for which $\mathrm{S} \mathrm{Vs}$, we are giving a distinctive sort of psychological explanation of her $\mathrm{V}$-ing-one which cites the considerations that motivate her to V. This sort of psychological explanation of S's V-ing is sometimes called a "rationalizing explanation". 4

${ }^{4}$ The contrast between $(\mathrm{N})$ and $(\mathrm{E})$ is often described by saying that in $(\mathrm{N}), \mathrm{M}$ is a "normative reason" for $\mathrm{S}$ to $\mathrm{V}$, whereas in $(\mathrm{E}), \mathrm{M}$ is $\mathrm{S}$ 's "motivating reason" for $\mathrm{V}$-ing. I have no in-principle objection to this terminology. But in practice, the terminology often comes packaged with substantive assumptions about the relationship between normative and motivating reasons, and between claims like $(N)$ and $(E)$. Since that relationship is part of what's at issue here, I prefer to avoid framing things in these terms. 
As they are usually understood, and as I will understand them, rationalizing explanations like (E) do not imply normative claims like $(N)$. If $(E)$ is true, then $M$ is what motivates S's V-ing; but it doesn't necessarily follow that M really is a reason for $\mathrm{S}$ to $\mathrm{V}$ - that it provides some degree of justification for S's V-ing. As is unfortunately all too familiar, the considerations that motivate people to do things are often no justification at all for them to do those things.

(A terminological aside: we often express rationalizing explanations like (E) in slightly different ways. For instance, instead of saying that "such-and-such is the reason for which S Vs", we might instead say that:

"S Vs for the reason that such-and-such", or that

"the reason why S Vs is such-and-such", or that

"S Vs because such-and-such".

The last two sorts expressions need a bit of care, however. Although they can be used to express the claim that $\mathrm{M}$ is the reason for which $\mathrm{S} \mathrm{Vs}$, they also have broader explanatory uses. In particular, they can be used to give explanations of S's V-ing which are merely causal..$^{5}$ Consider: "The reason why Sarah is frolicking in the sea is that she's had too much to drink"; or "Ben wants to run for President because he fell over and hit his head". These are not rationalizing explanations. The first explains Sarah's frolicking by citing a mere cause of her frolicking, not by giving the reason for which she is frolicking-if indeed there is one. And the second explains Ben's wanting to run for President by citing a mere cause of his wanting to run, not by giving the reason for which he wants to run-if indeed there is one. However, so long as we're aware of their broader uses, expressions of these kinds shouldn't cause us any trouble; and since they often allow for more natural wording, I will allow myself to use them. Unless I indicate otherwise, you should assume that I am using them to give rationalizing explanations.)

\footnotetext{
${ }^{5}$ I don't mean to imply that rationalizing explanations aren't causal explanations, because they are. My point is that not all causal explanations are rationalizing explanations. Some causal explanations are merely causal: causal but not rationalizing. And the "reason why" and "because" locutions can be used to give such merely causal explanations.
} 
Although these two sorts of claims- $(\mathrm{N})$ and (E) — are distinct, many philosophers think that there is nevertheless a link between them. This link has been most widely discussed in relation to reasons for action. In that context the thought is this: if $\mathrm{M}$ is a reason for $\mathrm{S}$ to perform some action $\mathrm{F}$, then $\mathrm{M}$ could be the reason for which (or one of the reasons for which) S Fs. A reason for an agent to perform an action must be such that the agent could perform the action, at least in part, for that reason. Call this requirement the:

Explanatory Constraint on Reasons to Act. If $\mathrm{M}$ is a reason for $\mathrm{S}$ to perform some action $\mathrm{F}$, then $\mathrm{M}$ could be the reason for which (or one of the reasons for which) S Fs.

Bernard Williams is a well-known defender of this constraint, but it's very widely accepted. ${ }^{6}$

If this explanatory constraint on reasons to act is correct, then it's natural to regard it as reflecting something general about reasons, rather than something specifically about reasons to act. So it's natural to think that there will be a parallel constraint on reasons to have mental states like intentions and beliefs.

In the case of intentions, the constraint will be this:

Explanatory Constraint on Reasons to Intend. If $\mathrm{M}$ is a reason for $\mathrm{S}$ to intend to perform some action $\mathrm{F}$, then $\mathrm{M}$ could be the reason for which (or one of the reasons for which) $\mathrm{S}$ intends to $\mathrm{F}$.

The idea behind the Explanatory Argument is that facts which aren't reasons to F don't satisfy this explanatory constraint with respect to intentions to F. A fact which isn't a reason for one to $\mathrm{F}$ also isn't a reason for one to intend to $\mathrm{F}$, and that's because it couldn't be the reason for which (or one of the reasons for which) one intends to F.

We can set out the argument as follows, with the first premise, (P1), being the explanatory constraint on reasons to intend:

${ }^{6}$ See, e.g., Williams [1980] 1981, p. 107; Williams 1995, pp. 38-39. Other recent endorsements include Parfit 1997, p. 114 n. 28, and Dancy 2000, p. 101. 


\section{The Explanatory Argument}

(P1) If $\mathrm{M}$ is a reason for $\mathrm{S}$ to intend to $\mathrm{F}$, then $\mathrm{M}$ could be the reason for which (or one of the reasons for which) $\mathrm{S}$ intends to $\mathrm{F}$.

(P2) If $\mathrm{M}$ is not a reason for $\mathrm{S}$ to $\mathrm{F}$, then it is not the case that $\mathrm{M}$ could be the reason for which (or one of the reasons for which) $S$ intends to $F$.

(C1) So, if $\mathrm{M}$ is not a reason for $\mathrm{S}$ to $\mathrm{F}$, then $\mathrm{M}$ is not a reason for $\mathrm{S}$ to intend to F. [From (P1), (P2).]

(C2) So, there are no state-based reasons to intend. [From (C1), by the definition of a state-based reason.]

From now on I'll often omit explicit mention of the qualifications ("or one of the reasons for which") in premises (P1) and (P2). But you should take them as read throughout.

Should we accept this Explanatory Argument? The move from the two premises to (C1) is valid, and the move from (C1) to (C2) relies only on the definition of a statebased reason. So if we want to resist the argument, we'll need to reject one of the premises. Beginning in the next section, I'll look at each of the premises in turn.

Before I do that, however, I need to address an interpretive question: What is the nature of the "could" modality in (P1) and (P2)?

I take it that $\mathrm{M}$ could be the reason for which $\mathrm{S}$ intends to $\mathrm{F}$ just in case it is possible that: $\mathrm{S}$ intends to $\mathrm{F}$ and $\mathrm{M}$ is the reason for which $\mathrm{S}$ intends to $\mathrm{F}$. But what kind of possibility is at issue? There are two natural contenders: some kind of psychological possibility, or some kind of conceptual possibility.

There's a lot that can be said about what these two kinds of possibility amount to, and about which provides the better reading of the Explanatory Argument; but I don't need to make a choice between them here. My strategy for responding to the Explanatory Argument will allow me to remain neutral about what the best interpretation is.

Here's why. Although I'll raise some worries about the first premise, (P1), my main target here is the second premise, (P2). In Sections 4 and $5 \mathrm{I}$ will present some cases that I take to be counter-examples to (P2). These cases will show that even if M isn't a reason for one to $\mathrm{F}$ (and even if one believes that), still it is psychologically possible for one to intend to $\mathrm{F}$, and for $\mathrm{M}$ to be the reason for which one intends to $\mathrm{F}$. Indeed, the 
cases make it very plausible that we actually often intend for such reasons. If intending for such reasons is psychologically possible, then it is also conceptually possible: the psychological possibilities are a subset of the conceptual possibilities. So if I'm right about these cases, they show that (P2) is false whether we read the modality as psychological or conceptual. That is why I can remain neutral about what the modality is.

\section{Evaluating (P1)}

Let's now turn to look at the premises of the Explanatory Argument, starting with (P1), the explanatory constraint on reasons to intend. As with the parallel constraint on reasons to act, this constraint is rarely argued for. Most who accept the constraint seem to treat it as obvious-perhaps as part of the concept of a reason. However, there are some reasons to be suspicious of it.

Consider a few cases (these raise worries both for the constraint on reasons to act and for the constraint on reasons to intend):

\section{Case 1: Obsessive Killjoys}

Mary is an obsessive killjoy. For some reason or other (perhaps her unusual upbringing), she is quite incapable of ever doing anything that she believes would be fun. It's not that Mary is incapable of having fun; she does sometimes catch herself having fun, and when she does have fun, it's good for her. It's just that she is incapable of doing anything that she believes would be fun. If she believes something would be fun, then she doesn't do it, or continue to do it. As it happens, there is a concert on tonight, and if Mary goes, she'll have fun. Given how Mary is, the fact that going to the concert would be fun couldn't be the reason for which Mary goes to the concert. (The fact that going to the concert would be fun is the reason for which Mary goes to the concert only if Mary believes that going to the concert would be fun; but we've just said that she is incapable of doing anything that she believes would be fun.) Does it follow that the fact that going to the concert would be fun isn't a reason for Mary to go? Intuitively, no: having fun is after all good for her. 
Similarly for intentions. Given how Mary is, the fact that going to the concert would be fun couldn't be the reason for which Mary intends to go to the concert. Does it follow that the fact that going to the concert would be fun isn't a reason for Mary to intend to go? Intuitively, no: having fun is after all good for her.

\section{Case 2: Surprise Parties ${ }^{7}$}

Will very much enjoys surprise parties, that is, parties that he isn't aware of in advance. As it happens, there is a surprise party waiting for him next door-a party that he isn't aware of. The fact that there is a surprise party waiting for him next door couldn't be the reason for which Will goes next door. (The fact that there is a surprise party waiting for him next door is the reason for which Will goes next door only if Will believes that there is a surprise party waiting for him next door; but that's not a belief that it is possible for him to have. Will can't believe that there is a surprise party waiting for him next door-a party that he isn't aware of. $)^{8}$ Does it follow that the fact that there is a surprise party waiting for him next door isn't a reason for Will to go next door? Intuitively, no: he does after all enjoy surprise parties.

Similarly for intentions. The fact that there is a surprise party waiting for him next door couldn't be the reason for which Will intends to go next door. Does it follow that the fact that there is a surprise party waiting for him next door isn't a

${ }^{7}$ The template for this example comes from Mark Schroeder (2007, pp. 33, 165-166).

${ }^{8}$ Here's a different argument for the same conclusion, one which doesn't rely on claims about what it is possible to believe. The "reason for which" locution is factive: $M$ is the reason for which $\mathrm{S}$ Vs only if it is the case that $\mathrm{M}$. Therefore, the fact that there is a surprise party waiting for him next door is the reason for which Will goes next door only if both (i) Will believes that there is a surprise party waiting for him next door; and (ii) there is a surprise party waiting for him next door. But (i) and (ii) are inconsistent. If Will believes that there is a surprise party waiting for him next door, then there isn't a surprise party waiting for him next door-for it's no longer a surprise. So even if we concede that it is possible for Will to have the belief in (i), the fact that there is a surprise party waiting for him next door still couldn't be reason for which Will goes next door. The factivity of the "reason for which" locution (along with the nature of surprises) rules that out. 
reason for Will to intend to go next door? Intuitively, no: he does after all enjoy surprise parties.

\section{Case 3: Mercenary "Friendships"}

Although Jill doesn't like Rose much, she has one very good reason to be friends with her. Jill is constantly getting into financial trouble, and if Jill and Rose were friends, then Rose, who is very rich, would lend Jill money if she needed it. Intuitively, the fact that Rose lends money to her friends is a reason for Jill to be friends with Rose. But it couldn't be the reason for which Jill is friends with Rose. Why not? Because then their relationship wouldn't be a friendship. If the reason for which Jill is in a certain relationship with Rose is that Rose lends money to her friends, then their relationship isn't a friendship. At best, it's the kind of relationship that would have been a friendship, if the reason for which Jill had been in the relationship had been of the right kind.

Like the first two cases, this third case raises a worry for the explanatory constraint on reasons to act; but it's trickier to extend this last example to cover intentions. Even if the fact that Rose lends money to her friends couldn't be the reason for which Jill is friends with Rose, perhaps that fact could be the reason for which Jill intends to be friends with Rose. For Jill's intention might be an intention to be friends with Rose for the right reasons - where the "for the right reasons" attaches to the being and not the intending.

These are admittedly unusual cases, and I don't expect them to be uncontroversial. Still, they make it clear that those who want to rely on the explanatory constraint do need to say something — and more than they usually say — to defend the constraint. ${ }^{9}$

${ }^{9}$ If the cases do work, which versions of the explanatory constraint do they work against? Obsessive Killjoys looks as if it would be a counter-example only to a psychological version of the explanatory constraint. Surprise Parties and Mercenary "Friendships" are more complicated, but it's arguable that they would also be counterexamples to a conceptual version of the explanatory constraint. It seems not merely psychologically but also conceptually impossible for Will to go next door because there is a surprise party waiting for him next door, or for Jill to be friends with Rose because Rose lends money to her friends. 
Although I have reservations about the explanatory constraint, I don't want to get bogged down in trying to assess it, because there is a bigger problem with the Explanatory Argument to worry about. For now, let's assume that the explanatory constraint is correct. If it turns out to be false, so much the worse for the Explanatory Argument.

\section{Evaluating (P2)}

What about the second premise of the Explanatory Argument, (P2)? I repeat it here for convenience:

(P2) If $\mathrm{M}$ is not a reason for $\mathrm{S}$ to $\mathrm{F}$, then it is not the case that $\mathrm{M}$ could be the reason for which (or one of the reasons for which) $\mathrm{S}$ intends to $\mathrm{F}$.

Many philosophers have endorsed (P2). ${ }^{10}$ They think that the reasons for which one intends to do something are always, and could only be, reasons to do that thing. Put slightly differently: they think that the only considerations that could motivate one to intend to do something are considerations which are reasons to do that thing. This view is a fairly natural one; I suspect that it is most people's first stop. But when one looks at it carefully, I think it's clear that it doesn't stand up to scrutiny.

To see one problem with (P2), consider Erica's case. It is Tuesday, and Erica is in the pub with a beer before her on the table. The fact that it is Tuesday is, let's suppose, not a reason for Erica to drink the beer. But suppose Erica believes, falsely, that that fact is a reason for her to drink the beer. It should be uncontroversial that, in such a case, the fact that it is Tuesday could be the reason for which Erica intends to drink the beer. Erica could intend to drink the beer, and the fact that it is Tuesday could be the reason for which she intends to drink it. Since, by hypothesis, the fact that it is Tuesday is not a reason for Erica to drink the beer, Erica's case is a counter-example (P2).

In general, let a false belief case be a case in which $\mathrm{M}$ is not a reason for $\mathrm{S}$ to $\mathrm{F}$, but in which $\mathrm{S}$ believes, falsely, that $\mathrm{M}$ is a reason for her to $\mathrm{F}$. Many false belief cases will be cases in which $\mathrm{M}$ could be the reason for which $\mathrm{S}$ intends to $\mathrm{F}$. Erica's case is an

${ }^{10}$ Prominent examples include Kavka (1983, p. 35), Hieronymi (2005; 2006), and Shah (2008). 
example. Such cases are counter-examples to (P2) - though as we'll in the next section, they aren't the only counter-examples.

How might proponents of the Explanatory Argument respond to false belief cases? They might try adjusting (P2) in some way. A natural move would be to modify the antecedent of (P2) so that it applies not to any fact which is not a reason for the agent to $\mathrm{F}$, but only to facts which the agent believes are not reasons for her to F. (Alternatively, they might modify the antecedent so that it applies only to facts which the agent does not believe are reasons for her to F. Parallel points will apply.) This would give us:

$(\mathrm{P} 2 *)$ If $\mathrm{S}$ believes that $\mathrm{M}$ is not a reason for her to $\mathrm{F}$, then it is not the case that $\mathrm{M}$ could be the reason for which (or one of the reasons for which) $\mathrm{S}$ intends to $\mathrm{F}$.

False belief cases do not generate counter-examples to $(\mathrm{P} 2 *)$, since in false belief cases the antecedent of $(\mathrm{P} 2 *)$ is false.

If we replace $(\mathrm{P} 2)$ with $(\mathrm{P} 2 *)$ we get a new version of the Explanatory Argument, with a new conclusion:

\section{Revised Explanatory Argument}

(P1) If $\mathrm{M}$ is a reason for $\mathrm{S}$ to intend to $\mathrm{F}$, then $\mathrm{M}$ could be the reason for which (or one of the reasons for which) $\mathrm{S}$ intends to $\mathrm{F}$.

$\left(\mathrm{P} 2^{*}\right)$ If $\mathrm{S}$ believes that $\mathrm{M}$ is not a reason for $\mathrm{S}$ to $\mathrm{F}$, then it is not the case that $\mathrm{M}$ could be the reason for which (or one of the reasons for which) $\mathrm{S}$ intends to $\mathrm{F}$.

(C1*) So, if $\mathrm{S}$ believes that $\mathrm{M}$ is not a reason for $\mathrm{S}$ to $\mathrm{F}$, then $\mathrm{M}$ is not a reason for $\mathrm{S}$ to intend to F. [From (P1), $(P 2 *)$.]

$\left(\mathrm{C} 2^{*}\right)$ So, if $\mathrm{S}$ believes that $\mathrm{M}$ is not a reason for $\mathrm{S}$ to $\mathrm{F}$, then $\mathrm{M}$ is not a statebased reason for $\mathrm{S}$ to intend to $\mathrm{F}$. [From $\left(\mathrm{Cl} 1^{*}\right)$, by the definition of a state-based reason.]

Notice that even if this revised argument is sound, it isn't an argument against the possibility of state-based reasons to intend. The new conclusion doesn't rule out the possibility of reasons to intend to $F$ which are not reasons to F. Nevertheless, if this new conclusion were true, that would still be an interesting result. 
However, this revised argument isn't sound either. In the next section I will present some cases which show that both the original premise (P2) and the revised premise $\left(\mathrm{P} 2^{*}\right)$ are false. In addition to showing that the Revised Explanatory Argument is unsound, these cases will therefore give us further grounds to reject the original Explanatory Argument—grounds which are independent of false belief cases.

\section{More Counter-Examples}

Before I get to the cases, one quick comment about their structure. So far I deliberately haven't said much about the kinds of facts that are supposed to be state-based reasons to intend. But it will help now to make things a bit more concrete. In order to do this, I will focus on a class of facts that are particularly good candidates for being a statebased reasons to intend: namely, facts about the possible benefits of intending.

To be a bit more precise, it's natural for a defender of state-based reasons to think that facts of the form S's intending to F might lead to $B$ (where B is some particular beneficial outcome) can be state-based reasons for $S$ to intend to F. All the candidates for state-based reasons that I will consider in this section are facts of this form.

\subsection{The Toxin Puzzle}

The most widely discussed case in this area is Gregory Kavka's Toxin Puzzle. ${ }^{11}$ However, the Toxin Puzzle has some complicating features that make it a bad place to start one's thinking about state-based reasons. Verdicts about the Toxin Puzzle should come pretty close to the end of the investigation, not the beginning.

Kavka asks us to consider a case in which an agent's intending to perform a certain action (drinking a harmful but non-lethal vial of toxin at noon the next day) might be beneficial. But the case has some unusual features. First, most people think that the agent ought not to perform the action; indeed, that she has no reason at all to perform it. ${ }^{12}$ Furthermore, it's tempting to think that anybody who was in the agent's situation

${ }^{11}$ See Kavka 1983.

${ }^{12}$ This is the standard view, and I believe the correct one; but there are some dissenters. David Gauthier is one example: see, e.g., Gauthier 1994, pp. 707-709; Gauthier 1998. 
would believe those normative claims. Second, it's also tempting to think that anybody who was in the agent's situation would not perform the action, and would believe that. ${ }^{13}$ These features introduce unnecessary complications, and so it's better to begin with cases that don't have these features. The two cases that I consider below are designed with this in mind.

Simplifying in order to screen out these distracting features is an important methodological step, not just for our immediate purpose of assessing the Explanatory Argument, but also for the eventual resolution of more complicated cases. Once we are clear about what is going on in the simpler cases, we can then think about how the addition of extra features, such as those present in the Toxin Puzzle, might change things. (I'll have a bit more to say about the Toxin Puzzle in Section 6.1.)

\subsection{Arm Raising}

So, consider the following variation on the Toxin Puzzle:

Arm Raising. An eccentric but trustworthy billionaire promises me a million dollars if I intend, in thirty seconds from now, to raise my arm in one minute from now. The billionaire doesn't care about whether or not I actually raise my arm in a minute from now; she's only interested in what intentions I have in thirty seconds from now. She has access to a method that will allow her to determine with great reliability whether or not I have the intention at the relevant time. If she concludes in thirty seconds from now that I do have the intention at that time, then she will straightaway_and irrevocably_-deposit the money in my bank

${ }^{13}$ Would anybody who found herself in the Toxin Puzzle believe that she wouldn't drink the toxin? Either the answer to this question is a matter of stipulation-we build it into the description of the puzzle - or else it is an empirical, psychological question. In the latter case, a lot will of course depend on how exactly the puzzle is described, and in particular on what other beliefs the person has. But in the bare-bones Toxin Puzzle (the puzzle as described in the first paragraph of Kavka 1983), it seems to me rather unlikely that the answer is "yes". No doubt some people would believe that they wouldn't drink the toxin; perhaps even many would. But not everyone would. Human psychology is too varied and flexible for that. What about people who are unreflective? Or irrational? What about people who believe that they are super-resolute: that they will do whatever they intend to do? And so on. 
account, and the transaction will be complete before the time comes for me to carry out the intention (she'll make an instantaneous electronic funds transfer). However, if she concludes in thirty seconds from now that I don't have the intention at that time, then I don't win the money. I know all of this.

Notice that, given the way that this case is set up, whether or not I actually raise my arm in a minute from now will have no effect on whether or not I win the money. In a minute from now, when the time comes for me to raise my arm, it will already have been determined whether or not I have won the money. Nothing I can do then will affect my bank account.

Let the Prize Fact be the fact that my intending to raise my arm might win me a million dollars. Given what I said in the last paragraph, the Prize Fact is not a reason for me to actually raise my arm. It might well be a reason for me to do something; but it's not a reason for me to raise my arm. It is also very plausible that the Prize Fact is a reason for me to intend to raise my arm; in which case, it is a state-based reason for me to intend to raise my arm. For the moment, however, I'm not interested in the final verdict about whether or not the Prize Fact is a state-based reason. For now, set aside that larger issue and consider the following more specific question.

Suppose I believe, correctly, that the Prize Fact is not a reason for me to actually raise my arm. Could I nevertheless intend to raise my arm, and intend to do so because (or at least in part because) so intending might win me a million dollars? Could the reason for which (or one of the reasons for which) I intend to raise my arm be that so intending might win me a million dollars?

I think the answer is yes: I could indeed intend to raise my arm for that reason. I admit that I'm not completely confident of this, because I'm not completely confident that I know all the nuances of my own psychology. Still, I'm fairly sure that I could do it, perhaps aided by a little bit of psychological training; and I'm quite sure that someone could do it. Even if I myself don't have the psychology for the job, there are surely people who do. Arm Raising (or a version of it in which a psychologically suitable agent takes my place) is therefore a counter-example to both (P2) and (P2*). 


\subsection{Movie Decisions}

The Arm Raising case is obviously artificial, but there are also many everyday counterexamples to (P2) and (P2*). For instance, consider:

Movie Decisions. Claire is trying to decide whether to go and see a movie tonight, or else stay home and have dinner with her friends. The pros and cons are evenly balanced: although the advantages and disadvantages of the two options are rather different, there's nothing much to choose between them. Claire has been thinking about the matter for a while now, and her dithering is distracting her from what she is supposed to be doing. She would therefore like to settle the issue quickly, so she can put the matter out of her mind and get on with some work this afternoon. And from past experience of cases like this, Claire knows that once she does make a decision, it is likely to have just that effect-for she is good at moving on once she has made a decision.

Let the Strategic Fact be the fact that Claire's deciding, and so intending, to go to the movie tonight is likely to put the matter out of her mind and allow her to get on with her work. This fact is not a reason for Claire to actually go to the movie. But it is plausibly a reason for her to intend to go the movie; in which case it's a state-based reason for her to intend to go the movie. For the moment, however, set aside that larger issue and consider the following more specific question.

Suppose Claire believes, correctly, that the Strategic Fact is not a reason for her to go to the movie. Could she nevertheless intend to go the movie, and intend to do so because (or at least in part because) her so intending is likely to put the matter out of her mind and allow her to get on with her work? Surely the answer is again yes. Movie Decisions therefore gives us another counter-example to $(\mathrm{P} 2)$ and $(\mathrm{P} 2 *)$.

Cases like Movie Decisions are particularly important because they make it clear that counter-examples to $(\mathrm{P} 2)$ and $(\mathrm{P} 2 *)$ need not be based on artificial, one-off cases like Arm Raising (or even worse, the Toxin Puzzle). Counter-examples also arise in everyday contexts. The key point to note here is that there are a range of distinctive benefits which are regularly generated by intentions in everyday contexts. ${ }^{14}$

\footnotetext{
${ }^{14}$ For an influential discussion of these benefits, see Bratman 1987.
} 
One example, which is illustrated by Movie Decisions, is that intentions often have allocation benefits: by settling in advance what one is going to do, intending to do something can curtail deliberation, and thus free up valuable resources (time, deliberative effort, and so on) to be spent on other tasks. Another example is that intentions often have both intra- and inter-personal co-ordination benefits: by committing us to performing certain actions, intending to do something can generate fixed points which help us to plan and co-ordinate our behaviour. If Claire now decides, and so intends, to go to the movie tonight, that will do more than put the matter out of her mind and allow her to get on with her work. It will also give her time to confirm with Jack that she'll be going to the movie; to buy cheap tickets in advance; and to warn her friends that she won't be home for dinner, so that they don't cook extra for her.

These familiar sorts of benefits of intending crop up everywhere, and in many of these cases the situation is the same as it is in Movie Decisions. With respect to these familiar sorts of benefits of intending, it seems clear that we can, and often do, intend to do things because (or at least in part because) so intending might have those benefits. And we can do all this while recognizing - what is usually the case - that these facts about the possible benefits of intending are not reasons to actually perform the action intended. These everyday cases have been surprisingly neglected in the debate over state-based reasons to intend. ${ }^{15}$ But once we pay attention to them, we can see that they provide a fertile source of counter-examples to $(\mathrm{P} 2)$ and $(\mathrm{P} 2 *) .{ }^{16}$

${ }^{15}$ Clarke 2007 is an exception.

${ }^{16}$ Another interesting set of everyday cases to think about involve what Richard Holton (2003) calls "resolutions". According to Holton, "[r]esolutions are intentions part of whose function is to defeat contrary inclinations" that one expects to have (2003, p. 42). It's not entirely clear how to cash out this notion of "function". But here's one thought: to resolve to $\mathrm{F}$ is (perhaps among other things) to intend to $\mathrm{F}$, and to so intend in part because so intending might help one to defeat contrary inclinations. Knowing that I will be tempted to drink too much at dinner, I resolve to have no more than two drinks; that is (perhaps among other things), I intend to have no more than two drinks, and I so intend in part because so intending might help me to resist temptation. The fact that intending to have no more than two drinks might help me to resist temptation is not itself a reason for me to have no more two drinks; and I know that. So if it is possible for me to form such a resolution, that would be another counter-example to 
One last point. There is an interesting difference between Arm Raising and Movie Decisions which has to do with the source of the state-based reasons to intend. ${ }^{17}$

Say that a fact is a general incentive for one to make up one's mind about whether to F just in case, for all $\mathrm{G}$ such that intending to $\mathrm{G}$ is a way of making up one's mind about whether to F, the fact is a reason for one to intend to G. In Movie Decisions, Claire's state-based reason to intend to go to the movie derives from a general incentive for her to make up her mind about whether to go to the movie; whereas the parallel claim is not true in Arm Raising. My state-based reason to intend to raise my arm - that my so intending might win me a million dollars - does not derive from any general incentive for me to make up my mind about whether to raise my arm, for I don't have any such general incentive. ${ }^{18}$

I've discovered that some people react to Arm Raising and Movie Decisions in different ways. While they're happy to agree with my claims about Movie Decisions, they're less convinced about Arm Raising. But why should we treat the cases differently? One possibility is that it has something to do with the differences in general incentives. Perhaps cases where agents have a general incentive to make up their mind on some question should be treated differently from cases where they do not?

I'm not sympathetic to this move. If general incentives to make up one's mind can be a source of state-based reasons to intend, it's hard to see why state-based reasons couldn't also come from other sources - as they do (I claim) in Arm Raising. Anyway, for present purposes I don't need to rely on Arm Raising. Cases like Movie Decisions are enough on their own to undermine both versions of the Explanatory Argument. And they are also enough to make a strong, positive case for the existence of state-based reasons to intend (more on this positive point at the end of the paper).

(P2) and (P2*).

17 Thanks to Mark Schroeder for pressing this point.

${ }^{18}$ Nothing about the billionaire's promise generates a general incentive for me to make up my mind about whether to raise my arm. This is because nothing about the billionaire's promise generates a reason for me to intend not to raise my arm-even though intending not to raise my arm is a way of making up my mind about whether to raise my arm. 


\section{Further Comments}

That completes my case against the Explanatory Argument. I'll finish with two further sets of comments.

\subsection{Belief-Constraints on Intentions}

The following belief-constraint on intentions is widely accepted: necessarily, if one believes that one won't $\mathrm{F}$, then one does not intend to $\mathrm{F} .{ }^{19}$ This implies that one cannot both believe that one won't F, and intend to F. Might this belief-constraint in some way help the Explanatory Argument?

Well, the belief-constraint doesn't support premise (P2) of the Explanatory Argument, but it does arguably entail yet another weaker version of the second premise. Suppose $S$ believes that she won't F. Given the belief-constraint, it seems to follow that S cannot intend to $\mathrm{F}$ (or at least, that seems to follow if it's also true that $\mathrm{S}$ cannot not believe that she won't F-so let's assume that that is also true) ${ }^{20}$ And if $\mathrm{S}$ cannot intend to F then, for all $\mathrm{M}$, it is not the case that $\mathrm{M}$ could be the reason for which $\mathrm{S}$ intends to $\mathrm{F}$. (If

${ }^{19}$ See, e.g., Adams 1986, p. 288; Bratman 1987, chs. 3, 8; Mele 1992, ch. 8. Some people accept a stronger belief-constraint: they think that, necessarily, if one doesn't believe that one will F, then one does not intend to F (e.g. Grice 1971; Harman [1976] 1999; Velleman 1989, ch. 4). With suitable adjustments, what I say will apply to this constraint as well.

${ }^{20}$ A little more slowly: on a natural reading of "can" and "cannot", the premise (A1) and the belief-constraint (BC):

(A1) S believes that she won't $F$

(BC) S cannot both believe that she won't F, and intend to F

imply the conclusion:

(C) $\mathrm{S}$ cannot intend to $\mathrm{F}$

only if we add the further premise:

(A2) S cannot not believe that she won't F.

So I'll assume for the purposes of the discussion in this section that (A2) is also true. 
one cannot intend to do something, then one cannot intend to do it for a reason either.) Finally, if that last claim is true, then it is also true in the special case where $\mathrm{M}$ is not a reason for $\mathrm{S}$ to $\mathrm{F}$.

So, the belief-constraint entails the following principle:

(P2\#) If $\mathrm{M}$ is not a reason for $\mathrm{S}$ to $\mathrm{F}$, and $\mathrm{S}$ believes that she will not $\mathrm{F}$ (and $\mathrm{S}$ cannot not believe that), then it is not the case that $\mathrm{M}$ could be the reason for which (or one of the reasons for which) $\mathrm{S}$ intends to $\mathrm{F}$.

I've formulated the principle in this way in order to make it transparent how it slots into the Explanatory Argument. This formulation is perhaps slightly misleading, since one of the claims in the antecedent, that $M$ is not a reason for $S$ to $F$, plays no essential role. As we just saw, if the belief-constraint entails (P2\#), that's because it entails a parallel principle for every fact $\mathrm{M}$, whether or not it is a reason for $\mathrm{S}$ to F. Still, the beliefconstraint does entail (P2\#).

(P2\#) is considerably weaker than (P2), and it isn't much help to the opponent of statebased reasons to intend. When we plug (P2\#) in as the second premise of the Explanatory Argument, we can derive only a very weak conclusion:

(C\#) If $\mathrm{M}$ is not a reason for $\mathrm{S}$ to $\mathrm{F}$, and $\mathrm{S}$ believes that she will not $\mathrm{F}$ (and $\mathrm{S}$ cannot not believe that), then $\mathrm{M}$ is not a state-based reason for $\mathrm{S}$ to intend to $\mathrm{F}$.

I don't deny that this conclusion might rule out some alleged cases of state-based reasons to intend. But many cases will remain untouched, since in many cases the agents won't have the belief profile which is needed to make the antecedent of the relevant instance of $(\mathrm{C} \#)$ true.

Take Arm Raising and Movie Decisions. In my description of these cases I didn't specify what sorts of beliefs Claire and I have about what we will do. So actually there are many versions of each of these cases-versions which differ according to what sorts of beliefs Claire and I have about what we will do. Now, we can certainly construct versions in which I believe that I won't raise my arm when the time comes (and cannot not believe that), and in which Claire believes that she won't go to the movie tonight (and cannot not believe that). In these special versions of Arm Raising 
and Movie Decisions, the antecedents of the relevant instances of $(\mathrm{C \#})$ are indeed true. So $(\mathrm{C \#})$ implies that these special cases don't generate examples of state-based reasons to intend: in these special cases, the fact that my intending to raise my arm might win me a million dollars is not a state-based reason for me to intend to raise my arm; and the fact that Claire's intending to go to the movie will have certain allocation and coordination benefits is not a state-based reason for her to intend to go to the movie. But of course, there are other versions of Arm Raising and Movie Decisions in which Claire and I don't have these special belief profiles; and in such cases, $(\mathrm{C \#})$ has no purchase.

Parallel points apply to the Toxin Puzzle. We can construct versions of the puzzle in which the agent believes she won't drink the toxin at noon the next day (and cannot not believe that). (C\#) implies that, in these versions of the puzzle, the fact that the agent's intending to drink the toxin might win the agent a million dollars is not a state-based reason for the agent to intend to drink the toxin. But, once again, there are other versions of the Toxin Puzzle in which the agent doesn't have this special belief profile; and in such cases, $(\mathrm{C \#})$ has no purchase. ${ }^{21}$

In summary: the belief-constraint on intending implies that where an agent has a very special sort of belief profile, the fact her intending to do something might be beneficial is not a state-based reason for her to intend to do that thing. This is an interesting observation, but it has limited broader significance. For the belief constraint is silent about those many cases-including versions of Arm Raising, Movie Decisions, and the Toxin Puzzle-in which the agent doesn't have the special belief profile.

\subsection{Rational Requirements}

Some philosophers think that, if the reason for which (or one of the reasons for which) one intends to $\mathrm{F}$ is something other than a reason to $\mathrm{F}$, then one is irrational. ${ }^{22}$ Their view is that, if we do intend for that sort of reason, then we violate a certain rational requirement. We can formulate it like this:

\footnotetext{
${ }^{21}$ See again $n .13$ above.

${ }^{22}$ Kavka once held something like this view: see Kavka 1978, p. 292. For a similar claim see Farrell 1993, p. 59.
} 
Motivational Reasons Requirement. Rationality requires of $\mathrm{S}$ that: if $\mathrm{M}$ is not a reason for $\mathrm{S}$ to $\mathrm{F}$, then $\mathrm{M}$ is not the reason for which (or one of the reasons for which) $\mathrm{S}$ intends to $\mathrm{F}$.

If the Motivational Reasons Requirement were correct, would it support (P2)? No, because (P2) is a claim about what is possible, not about what is rational. What (P2) says is that, if $\mathrm{M}$ is not a reason for $\mathrm{S}$ to $\mathrm{F}$, then $\mathrm{M}$ could not be the reason for which $\mathrm{S}$ intends to F. And the Motivational Reasons Requirement doesn't imply that.

For my purposes in this paper, I thus have no particular beef with the Motivational Reasons Requirement. Since the requirement doesn't help the Explanatory Argument, I don't need to reject the requirement. But while I'm on the topic, I may as well say that I do think we ought to reject it.

I don't deny that there could be cases in which the reason for which an agent intends to $\mathrm{F}$ is something other than a reason to $\mathrm{F}$, and in which the agent is also irrational. That can no doubt happen. But in cases like this, it's not the reason for which the agent intends to $\mathrm{F}$ that makes her irrational. The agent's irrationality in such cases can always be traced to other sources.

For example, suppose that the reason for which Emily intends to $\mathrm{F}$ is something other than a reason to F, but she also believes that she ought not to F. (Suppose, for example, that Emily is in the toxin puzzle; that she intends to drink the toxin, and that the reason for which she so intends is that her so intending might win her the prize; but that she also believes she ought not to drink the toxin.) In such a case, Emily is irrational. But her irrationality has nothing to do with the reasons for which she intends to $F$. The explanation for why Emily is irrational is rather that rationality requires her not to have akratic intentions: rationality requires her not to both intend to $\mathrm{F}$ and believe that she ought not to F. It is the fact that Emily violates this rational requirement, and not the reasons for which she intends to $\mathrm{F}$, which explains why she is irrational.

As far as I can tell, the mere fact that the reason for which one intends to $\mathrm{F}$ is something other than a reason to F doesn't by itself make one irrational. Think again about our examples. If I intend to raise my arm because (or at least in part because) my so intending might win me the million dollars, would that by itself make me irrational? Surely not. If Claire intends to go to the movie because (or at least in part because) her so intending will put the matter out of her mind and allow her to get on with her work, 
would that by itself make her irrational? Surely not. These cases, and others like them, show that the Motivational Reasons Requirement is false.

\section{Conclusion}

My first conclusion is negative: the Explanatory Argument is unsound, because its second premise, $(\mathrm{P} 2)$, is false. Once we pay attention to the right sorts of examples it becomes clear that, contrary to (P2), the reasons for which we intend to do things can be, and often are, facts which are not reasons to do those things. (I also have some reservations about the first premise of the Explanatory Argument, (P1), though I haven't pressed those here.) If there are grounds to deny that there any state-based reasons to intend, they don't come from these sorts of explanatory considerations.

But we can also say something more positive, and more general. Although I don't claim it's a knock-down proof, I do think that the various examples that we've looked at make a strong positive case for the existence of state-based reasons to intend. It's a strong case because it appeals not just to baroque, one-off examples like Arm Raising (or even worse, the Toxin Puzzle), but also to prosaic, everyday examples like Movie Decisions. Indeed, although you wouldn't think it from reading the literature, it's the everyday examples that are really the bread-and-butter of the positive case for statebased reasons to intend.

Any argument against the possibility of state-based reasons will have to reject all these everyday examples. It will have to show that, even though intending often has these familiar sorts of benefits (for instance, allocation and co-ordination benefits); and even though we are often aware of these benefits; and even though we can, and sometimes do, intend to do things because so intending might have these benefits-nevertheless, the fact that one's intending to do something might have such a benefit is never a reason for one so to intend. The prospects for such an argument seem to me pretty dim.

\section{References}

Adams, F. "Intention and Intentional Action: The Simple View", Mind and Language 1 (1986), pp. 281-301. 
Bratman, M. Intention, Plans and Practical Reason (Cambridge, MA: Harvard University Press, 1987).

Clarke, R. "Commanding Intentions and Prize-Winning Decisions", Philosophical Studies 133 (2007), pp. 391-409.

Dancy, J. Practical Reality (Oxford: Oxford University Press, 2000).

Enç, B. How We Act: Causes, Reasons, Intentions (Oxford: Clarendon Press, 2003).

Farrell, D. M. "Utility-Maximizing Intentions and the Theory of Rational Choice", Philosophical Topics 21(1) (1993), pp. 53-78.

Gauthier, D. “Assure and Threaten”, Ethics 104(4) (1994), pp. 690-721.

Gauthier, D. "Rethinking the Toxin Puzzle", in J. L. Coleman and C. W. Morris (eds.), Rational Commitment and Social Justice: Essays for Gregory Kavka (Cambridge: Cambridge University Press, 1998), pp. 47-58.

Goetz, S. C. "Reasons for Forming an Intention: A Reply to Pink", Mind 107 (1998), pp. 205-213.

Grice, H. P. "Intention and Uncertainty", Proceedings of the British Academy 57 (1971), pp. 263-279.

Harman, G. "Practical Reasoning" [1976], in Reasoning, Meaning and Mind (Oxford: Clarendon Press, 1999), pp. 46-74.

Hieronymi, P. “The Wrong Kind of Reason”, Journal of Philosophy 102(9) (2005), pp. 437-459.

Hieronymi, P. "Controlling Attitudes”, Pacific Philosophical Quarterly 87(1) (2006), pp. 45-74.

Holton, R. "How Is Strength of Will Possible?" in S. Stroud and C. Tappolet (eds.), Weakness of Will and Practical Irrationality (Oxford: Clarendon Press, 2003), pp. 36-67.

Kavka, G. “Some Paradoxes of Deterrence”, Journal of Philosophy 75 (1978), pp. 285302.

Kavka, G. "The Toxin Puzzle", Analysis 43 (1983), pp. 33-36.

Mele, A. R. Springs of Action: Understanding Intentional Behaviour (New York: Oxford University Press, 1992).

Mele, A. R. "Effective Deliberation about What to Intend: Or Striking it Rich in a Toxin-Free Environment”, Philosophical Studies 79 (1995), pp. 85-93.

Owens, D. Reason Without Freedom: The Problem of Epistemic Normativity (London: Routledge, 2000).

Parfit, D. "Reasons and Motivation", Proceedings of the Aristotelian Society Suppl. Vol. 71 (1997), pp. 98-130. 
Parfit, D. "Rationality and Reasons", in D. Egonsson et al. (eds.), Exploring Practical Philosophy (Aldershot: Ashgate, 2001), pp. 17-39.

Piller, C. "Normative Practical Reasoning", Proceedings of the Aristotelian Society Suppl. Vol. 75 (2001), pp. 195-216.

Schroeder, M. Slaves of the Passions (Oxford: Oxford University Press, 2007).

Shah, N. "How Action Governs Intention", Philosophers' Imprint 8(5) (2008).

Velleman, J. D. Practical Reflection (Oxford: Oxford University Press, 1989).

Williams, B. "Internal and External Reasons" [1980], in Moral Luck (Cambridge: Cambridge University Press, 1981), pp. 101-113.

Williams, B. "Internal Reasons and the Obscurity of Blame", in Making Sense of Humanity (Cambridge: Cambridge University Press, 1995), pp. 35-45. 